\title{
Vivir en un centro histórico en Latinoamérica. Percepciones de los hogares de profesionales en la ciudad de Puebla*
}

\section{Hélène Bélanger**}

En este artículo se presentan los resultados de una investigación sobre la "clase profesional" que se llevó a cabo en la ciudad de Puebla (México) en relación con sus percepciones sobre el centro histórico como hábitat. A pesar de que la UNESCO otorgó a la ciudad su reconocimiento como patrimonio mundial y pese a todos los programas diseñados para protegerla y mejorarla, su centro antiguo no parece ser uno de los "buenos sectores" (los barrios adecuados) para vivir. Los hogares de profesionales que viven en el centro histórico han satisfecho sus condiciones de vida; sin embargo varios de ellos, que no residen en el centro, tienen una percepción negativa sobre la seguridad, la limpieza, la infraestructura y las condiciones sociales del sector. Esta percepción perjudica la revitalización sociorresidencial del centro histórico de la ciudad.

Palabras clave: revitalización sociorresidencial, centro histórico, barrios, medio de vida, percepción.

En cualquier parte y cualquier época las familias de clase profesional ${ }^{1}$ prefieren vivir en los "buenos lugares" de la ciudad. Asimismo necesitan sentir que los separa cierta distancia de la gente que les causa desconfianza (Suttles, 1972). Kearns y Parkinson (2001) observan que el "barrio", término genérico usado aquí en el mismo sentido del

* La autora agradece a Mario Polèse y Anne-Marie Séguin, profesores del Instituto Nacional de Investigación Científica INRS (Institut National de la Recherche Scientifique) en su división de Urbanización, Cultura y Sociedad, sus comentarios y apoyo; a Salvador David Hernández y Elena Pou Madinaveitia la traducción del documento al español, y finalmente, a los tres evaluadores anónimos sus valiosos comentarios. Este trabajo de investigación fue financiado con recursos del Fondo de Investigaciones sobre la Naturaleza y las Tecnologías (Fonds de Recherche sur la Nature et les Technologies) del gobierno de la provincia de Quebec (Canadá) y del Instituto de Cooperación Internacional de México en su Secretaría de Relaciones Exteriores. Los errores y omisiones son de mi entera responsabilidad.

** École des Sciences de la Gestion, Département d'Études Urbaines et Touristiques, Université du Québec à Montréal. Correo electrónico: belanger.helene@uqam.ca.

${ }^{1}$ La clase profesional forma un subgrupo entre las clases medias que David Ley (1996) llama "nueva clase media" o "nueva clase cultural". Se distingue del resto de las clases medias por su modo de vida, que está vinculado a su evolución demográfica y económica y que tiene como características: la disminución del tamaño de los hogares, 
quartier français (noción que retomaremos), desempeña un papel importante en la identidad de las personas y en su posición social. Tal afirmación fue confirmada por las observaciones de Ward (1993) para el caso de las ciudades mexicanas. La identidad individual se construye alrededor de variables como el sexo, las características socioprofesionales y el perfil etnocultural, entre otras (Prochanski, 1978). A ellas se suma la identidad de lugar, que puede considerarse el componente espacial de la identidad individual. Este tipo de identidad relaciona el ambiente físico con otras variables ayudado por "las creencias, los valores, los sentimientos, las expectativas y las preferencias" (Prochanski, 1978: 163; traducción libre). Más allá de la realidad física y social de un lugar y de su representación por medio de los sentidos, su representación indirecta, es decir, el producto de su imaginación simbólica, afecta la identidad de la población que reside en ese lugar (véase Durand, 1968 y 1994, citado por Silva, 1992; Hiernaux, 2007; y Xiberras, 2002 sobre las formas de representación). Esto se ejemplificaría, como lo observan Dean y Hasting (2000, citados por Kearns y Parkinson, 2001), con los proyectos de revitalización, ya que éstos pueden ser influidos por la mala reputación del lugar en que se aplican. Las familias, entonces, pueden ver afectada la forma en que eligen su localización o relocalización residencial a causa de su percepción (verdadera o falsa) del medio ambiente físico y social en el que viven y en el que quisieran vivir, lo cual es a su vez influido por la representación social que existe sobre dicho entorno.

Este artículo es la tercera parte de una investigación que realizó la autora para su tesis de doctorado ${ }^{2}$ y que se refiere a la regeneración sociorresidencial de los barrios centrales de la ciudad de Puebla en México. Entendemos que la regeneración residencial es una reapro-

una mayor presencia de las mujeres en el mercado de trabajo, el aumento de la escolaridad, el trabajo en actividades de servicios superiores, entre otras. A causa de esta última característica preferimos el término "clase profesional" a "clase media", que suele utilizarse en estudios del mismo tipo. Las actividades llamadas de "servicios superiores" o "actividades cuaternarias", que como indica Ley incluyen los empleos en las finanzas, la investigación, el desarrollo, los servicios de consultoría, y las actividades gubernamentales (éstas abarcan la educación superior, la salud y el trabajo en las demás instituciones). La elección del término clase profesional toma en consideración la importancia de los trabajadores del Estado entre los profesionales en el caso mexicano.

${ }^{2}$ La tesis, titulada La régénérescense sociorésidentielle des quartiers centraux latino-américains: le cas de la ville de Puebla au Mexique (La regeneración sociorresidencial de los barrios centrales en la ciudad de Puebla en México) fue sustentada en Montreal en abril de 2005 en el INRS (Instituto National de la Investigación Científica) en su división de Urbanización, Cultura y Sociedad. 
piación que la clase profesional hace de la red residencial existente. Dicha red, que fue alterada físicamente después del declinamiento socioeconómico de su espacio físico, es ahora retomada como medio de vida por la clase profesional. Este aspecto, específico de la gentrificación, es el que mejor define el fenómeno que se produce en los barrios centrales antiguos. En ellos la población de la red residencial, que inicialmente alojó a los pobladores más afortunados, fue reemplazada por los pobladores más desprotegidos. Esto favoreció la degradación física de los antiguos inmuebles y el abandono de algunos de ellos.

Realizamos una treintena de entrevistas semidirigidas a los hogares profesionales con el fin de explorar sus percepciones (y a veces sus imaginarios) sobre el centro histórico de Puebla como lugar de residencia. Esta encuesta complementó una anterior de tipo cuantitativo sobre las aspiraciones residenciales de los hogares de clase profesional de Puebla. Nuestro objetivo principal era entender por qué, a pesar del interés en los barrios centrales como medio residencial, éstos no forman parte de los "buenos sectores" de la ciudad. Aunque el presente estudio no pretende ser una investigación sobre el imaginario urbano, se acerca sin embargo al tema con algunas de las preguntas que planteamos, entre ellas: ¿Cómo perciben el centro histórico los hogares de la clase profesional que podrían ser capaces de reocuparlo?, o mejor: ¿son las transformaciones físicas y sociales del centro histórico percibidas por la clase profesional? Nuestra hipótesis de trabajo es que, a pesar de los esfuerzos de revitalización, las condiciones físicas y sociales no han permitido, hasta el momento, cambiar notablemente la imagen que tiene la clase profesional sobre los barrios centrales como hábitat.

Puebla es una ciudad colonial de un millón trescientos mil habitantes que por características arquitectónicas fue reconocida en 1987 por la UNESCO como Ciudad del patrimonio mundial. Se han llevado a cabo varios esfuerzos por lograr la revitalización de su centro histórico, de cualidades arquitectónicas innegables. Estos esfuerzos, que comenzaron después de más de 20 años, se han encaminado a lograr la construcción de una imagen positiva del lugar. Pese a no ser un verdadero centro de negocios, abriga numerosas actividades relacionadas con los servicios profesionales, la educación superior y los servicios culturales. Las transformaciones sociodemográficas y socioeconómicas que están en curso en la capital del estado de Puebla han contribuido al desarrollo de una clase profesional cada vez más numerosa, similar a la que se ha reapropiado de los barrios centrales en muchas ciudades 
del mundo. Así pues, podemos decir que la ciudad de Puebla reúne un conjunto de factores que fomentan la revitalización sociorresidencial de su centro histórico, pero hasta el momento el centro antiguo no forma parte de los considerados "buenos vecindarios".

El interés de esta parte de la investigación, que utilizó herramientas cualitativas, está centrado en el análisis de las percepciones. El término percepción se usa aquí en un sentido amplio: incluye las percepciones sensoriales directas y las imaginarias que son capaces de influir en la producción de imágenes mentales del centro antiguo entre los hogares de clase profesional. A lo largo de las entrevistas fueron tratados varios temas, entre ellos los tipos de población que habitan el centro histórico; la evaluación que hacen del medio ambiente los profesionales que viven en el centro; y la identificación, entre los profesionales que residen en el centro, de los "pioneros" (Smith, 1996), ${ }^{3}$ de los "gentrificadores marginales" (Rose, 1996), ${ }^{4}$ y de los "residentes de siempre" (Bourdin, 1984). El término genérico barrio y sus variantes serán explorados y puestos en contexto para el caso mexicano antes de presentar los resultados de las entrevistas.

\section{Barrio, colonia, fraccionamiento. Los medios de vida}

Galster (2001) define barrio -traducción literal del término genérico francés: quartier-como el conjunto de características sociodemográficas, políticas, de relaciones sociales, de entorno edificado, de infraestructuras y de servicios públicos (entre otras) ancladas en el espacio. Esta amalgama de características aporta especificidad y da una identidad propia a cada barrio. En México el régimen de propiedad privada plasmado en el código civil ha fomentado el uso de tres palabras que se asimilan de manera distinta a la noción de barrio (como término genérico); éstas son: el barrio, la colonia y el fraccionamiento. En nuestra opinión estas denominaciones influyen sobre la represen-

${ }^{3}$ Término propuesto por Smith en analogía a los pioneros del viejo oeste de la colonización estadunidense. Estos pioneros, primeros conquistadores de los sectores centrales, habrían enfrentado malas condiciones físicas y sociales.

${ }^{4}$ Los gentrificadores marginales, tal como las familias monoparentales, no forman parte importante de los gentrificadores, sin embargo al decidir instalarse en los barrios centrales participan en la construcción de una imagen positiva de los lugares, lo que favorece las olas sucesivas de reapropiación de los hogares profesionales. 
tación que tiene la población sobre los diferentes espacios. El barrio se asimila por "analogía a los asentamientos de inmigrantes extranjeros a las orillas de las ciudades ibéricas del medioevo" (Méndez, 1987: 56). En las colonias españolas de México las autoridades delimitaron de esta manera los sectores reservados a la población indígena. Éstos, los barrios, constituyeron la periferia de las ciudades españolas ${ }^{5}$ durante la Colonia. Dichos espacios se otorgaban en préstamo a los indígenas durante un periodo que fijaban a su voluntad las autoridades virreinales. Hoy día el término barrio se refiere generalmente a esos antiguos asentamientos indígenas que rodeaban el centro español antiguo. A pesar de esta observación y en ausencia de un término alternativo utilizaremos el término en su acepción genérica, salvo indicación en contrario.

La adopción de la ley de fraccionamientos en los años cuarenta del siglo pasado facilitó el desarrollo de las colonias y de los proyectos de urbanización o fraccionamientos. Las colonias fueron las nuevas zonas que se desarrollaron en la periferia, contiguas al área urbana existente. Los fraccionamientos, en cambio, son espacios en algunas ocasiones cercados y vigilados por guardias armados apostados en la entrada (fraccionamientos cerrados) equivalentes al concepto estadunidense de gated communities. En estos lugares, creados para dar abrigo a varias clases sociales, habitan sobre todo las clases superiores mexicanas. El urbanizador suele parcelar e instalar los equipos y la infraestructura urbanos. Una vez realizado este procedimiento solicita la incorporación del fraccionamiento al municipio (Schteingart, 1989).

Hoy la cartografía oficial y el lenguaje común de la gente de Puebla incluyen esta terminología heredada del régimen de propiedad raíz mexicano. Como observa Silva (2006: 43), lo importante no es que la realidad percibida sea verdadera o falsa, sino que su representación se considere verdadera. Podemos suponer, de acuerdo con la fuerza de la terminología heredada, que las imágenes producidas con relación a los diferentes espacios de la ciudad alimentan el proceso de regeneración sociorresidencial de los barrios centrales.

${ }^{5}$ Algunos barrios fueron creados en medios rurales con el propósito de hospedar a la población indígena que trabajaba en ciertas industrias que se localizaban a gran distancia de la ciudad. 


\section{Los centros antiguos}

Los centros antiguos pueden modificar su representación sensible o radicalmente mediante su valoración simbólica. Ésta es la que transforma lo que ayer era un edificio deteriorado, incluso en ruinas, en algo más importante: un monumento histórico (Paz Arrellano, 1999; Bourdin, 1984). Con tal perspectiva "retocamos" y "escenificamos" los centros antiguos para su consumo turístico y lúdico (Choay, 1992). Los nuevos visitantes "viven en otros lugares, pero consumen en el centro antiguo $y$, algunas veces, se relacionan con sus habitantes. De esta manera tratan el centro como un territorio que les pertenece y al que, finalmente, imponen su ritmo" (Bourdin, 1984: 149-150; traducción libre).

¿Quién habita en estos espacios? En el caso de la ciudad de Ruán, Bourdin (1984) enumera cinco categorías de población. Entre ellas, tres merecen particular atención: los residentes de siempre, los jóvenes profesionales que desean aprovechar dichos barrios, y los consumidores de un modo de vida, una estética y una situación social diferentes (véase también Guerrero Lozano, 2000). Gracias a los profesionales que buscan una ubicación óptima, así como a los consumidores de signos y de imágenes, muchas ciudades del mundo han vivido la regeneración sociorresidencial de sus barrios centrales.

Según Jones y Varley (1999) y Ward (1993) la regeneración sociorresidencial parece ser poco frecuente en los centros antiguos latinoamericanos. Desde luego que ocurren transformaciones económicas y sociales que promueven la emergencia de una clase profesional capaz de interesarse por estos barrios, que presentan reconocidas cualidades arquitectónicas y urbanísticas y cuentan con una sólida infraestructura cultural, de diversión y de educación superior. Pero, pese a todo este conjunto de factores favorables que incluyen los "retoques" y la escenificación del patrimonio edificado perviven ciertos elementos negativos, como la mala calidad de las viviendas y de su infraestructura, el entorno social heterogéneo, el alto nivel de contaminación, y los problemas de inseguridad (reales o supuestos). Todas esas razones pueden explicar por qué las poblaciones más adineradas prefieren asentarse en los sectores situados en la periferia del núcleo central, que son más recientes y modernos. Pero, ¿cuál es la situación del centro histórico de Puebla? 
Puebla: un centro histórico reconocido

La ciudad de Puebla es un centro regional en el que la economía está siendo terciarizada. ${ }^{6}$ Tras consultar varios trabajos, hacer visitas de campo y observar un mapa de las actividades de servicios podemos asegurar que el centro de negocios se desarrolló a lo largo de los ejes de transporte que van desde el centro antiguo hacia la periferia de la ciudad, de ahí que el centro antiguo no fuera jamás tocado por grandes operaciones de revitalización urbana. Este fenómeno empezó a producirse una vez que la población de mayores recursos migró aproximadamente a partir de 1940 hacia el Barrio de La Paz, situado al oeste (mapa 1) y veinte años más tarde hacia el sur, con la construcción del centro Plaza Dorada. El abandono del centro colonial a las poblaciones menos afortunadas tuvo un efecto devastador sobre el ambiente físico (y social dirán algunos) de los barrios centrales antiguos. Varios edificios, moradas de la antigua aristocracia española, fueron subdivididos en pequeñas viviendas de una o dos habitaciones: las vecindades. A menudo éstas disponen únicamente de una cocina y de un baño para todo el edificio y son arrendadas por familias de escasos recursos. Pese a que son muchas las solicitudes de permisos de remodelación, muy pocos de estos edificios han sido convertidos en condominios debido principalmente a los problemas relacionados con el acceso al crédito y a las restricciones que impone la protección del patrimonio al limitar las transformaciones de las estructuras interiores (Gilbert y Varley, 1990; Jones y Varley, 1999). Es frecuente que los propietarios dejen que las residencias se deterioren debido al bajo monto de los arrendamientos que reciben, lo que las hace poco lucrativas. Ante tal realidad, los organismos de control de inmuebles patrimoniales se muestran incapaces de impedir su destrucción (Gilbert y Varley, 1990; Melé, 2003).

Hoy el centro monumental tiene una superficie aproximada de $7 \mathrm{~km}^{2}$ (mapas 1 y 2); incluye 2691 inmuebles catalogados como patrimonio repartidos en 391 manzanas construidas entre los siglos XVI y XIX. Se ha conservado su función simbólica: allí se encuentran el palacio municipal y la catedral de la plaza central (Zócalo), que continúa siendo un lugar de encuentro de todas las clases. Como muchas otras ciudades

${ }^{6}$ En 1980 buena parte de la población económicamente activa se dedicaba a las actividades de servicios: $51 \%$; de ellos, $31 \%$ a las actividades comerciales y el otro $20 \%$ a otras actividades de servicios. Menos de 20 años más tarde esta proporción pasó a más de $68 \%$ de la población económicamente activa, de la cual $32.6 \%$ trabaja en el sector comercial y $35.5 \%$ en las otras actividades de servicios. 


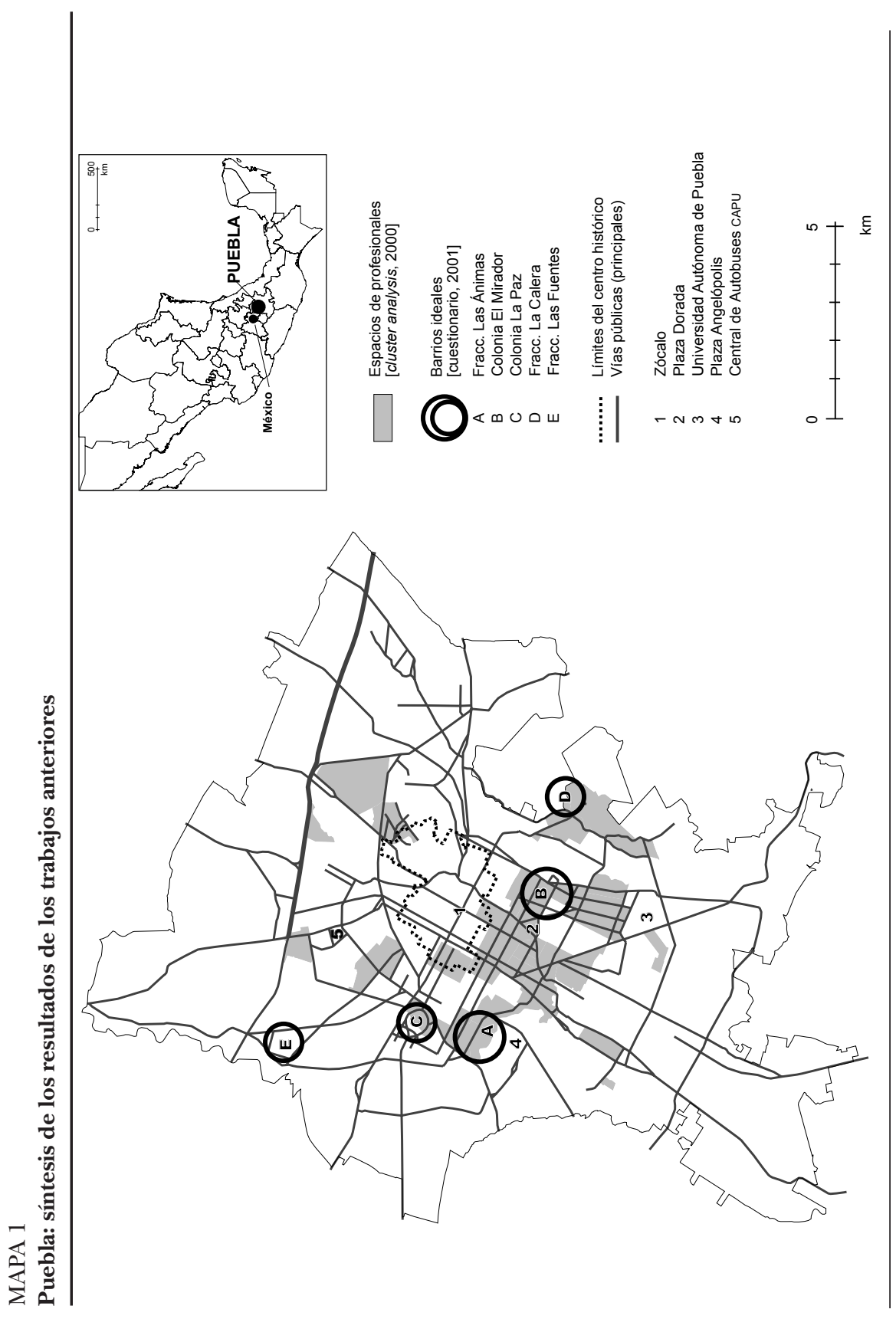


latinoamericanas, la ciudad de Puebla tiene una centralidad que se divide entre su centro colonial y su centro de negocios (Monnet, 1994).

A partir de 1980 Puebla ha sido objeto de varios programas de revitalización, que incluyeron entre otras tareas el desplazamiento de los mercados públicos y de las terminales de autobuses fuera del centro histórico, la construcción de vías peatonales, el mejoramiento del alumbrado público y la pintura de las fachadas. Las diversas jerarquías administrativas han aplicado muchos esfuerzos a la recuperación de la imagen original del centro colonial. El proyecto más ambicioso fue el del Paseo de San Francisco, que estaba localizado en la zona industrial del centro histórico y se proponía hacer de Puebla un destino turístico importante. En 1993 el Estado expropió las moradas de 4500 personas, principalmente pertenecientes a clases populares, quienes residieron en las 27 manzanas localizadas en su mayor parte en los barrios del oriente del centro histórico (Téllez Morales, 1998). Para seis de estas manzanas el Estado ideó un proyecto de complejo multifuncional que incluyó un centro de congresos. El resto de las manzanas se le vendió a inversionistas privados, lo que se supuso facilitaría su apropiación por la clase profesional. Sin embargo un análisis por sectores basado en los datos de los censos de 1999 y de 2000 y respaldado por trabajos anteriores (Bélanger, 2006) desvirtuó parcialmente esta hipótesis. El proyecto del Paseo de San Francisco duró varios años y sus efectos para el año 2000 eran marginales e indetectables mediante los datos censales sobre una base agregada AGEB (área geoestadística básica: la más pequeña unidad de recuento) (mapa 1).

Si bien según Jones y Varley (1999) la reapropiación del centro histórico de Puebla ya se logró con el establecimiento de algunos comercios y una infraestructura cultural, una encuesta realizada en forma de cuestionario en Puebla en el año 2001 a 118 profesionales, en el marco de nuestra investigación, demostró lo contrario. El centro histórico no parece ocupar un lugar importante en las aspiraciones residenciales de los profesionales (para conocer los resultados de esta encuesta véase Bélanger, 2005). Aunque la gran mayoría de los profesionales declara que suele acudir allí por motivos de trabajo o entretenimiento, el centro histórico no está incluido en la lista de los "barrios ideales" (mapa 1). Esto nos conduce a replantear la hipótesis según la cual esta falta de interés de los profesionales interrogados acerca del centro antiguo como medio residencial proviene de su percepción negativa sobre éste. O sea que la mala reputación del centro histórico oculta los esfuerzos públicos de revitalización y obstaculiza su regeneración sociorresidencial. 


\section{Metodología}

Para esta investigación se realizaron tres análisis sobre la regeneración sociorresidencial de los barrios centrales de Puebla. El trabajo de exploración que adoptamos favoreció una aproximación metodológica que privilegió la utilización de herramientas cualitativas y cuantitativas. De los análisis realizados, los dos primeros fueron ya publicados y presentamos aquí en detalle los resultados del tercero. El primer análisis se centró en la evolución del reparto sociorresidencial de los hogares (Bélanger, 2006) y resultó de un análisis por clusters en que se utilizaron los datos de los dos últimos censos. Este trabajo confirmó que hay una concentración residencial de los hogares de profesionales en los sectores de mayores ingresos, como La Paz y El Mirador. Los programas de revitalización del centro histórico no parecen haber incidido en el perfil sociorresidencial de sus residentes. El segundo análisis examinó las aspiraciones residenciales de los hogares de clase profesional y el lugar que ocupan en ellas los barrios centrales (Bélanger, 2005). Se basó en una encuesta por cuestionario que fue aplicada a 118 hogares de clase profesional con la intención de conocer su interés por una localización residencial central. Según los resultados de esta investigación los efectos de los programas de revitalización tardan en hacerse sentir debido a la reducida movilidad residencial de Puebla. Los profesionales consultados por medio de esta encuesta no tienen interés en una localización central; prefieren los barrios burgueses como La Paz y El Mirador o algunos fraccionamientos cerrados de las periferias. Sin embargo cuando se les preguntó si les gustaría vivir en el centro histórico, una parte no despreciable, uno de cada cuatro, respondió afirmativamente. Esta proporción aumenta a tres de cada cuatro cuando se les pregunta por los barrios limítrofes del centro histórico, que son más recientes y modernos y dan acceso a pie a la zona patrimonial. El tercer análisis, que desarrollamos aquí, aborda la percepción real o "imaginada" de los barrios centrales y más específicamente del centro antiguo como espacio residencial. Fue realizado a partir de una investigación cualitativa dirigida a comprender mejor por qué, a pesar de los numerosos esfuerzos de revitalización, el centro antiguo no forma parte de los "buenos sectores" de la ciudad.

Entre los meses de noviembre de 2001 y marzo de 2002 se realizaron 33 entrevistas semidirigidas a igual número de profesionales, a quienes se seleccionó por medio de un método de contacto progresivo, que se inició con cuatro contactos. La elección de las profesiones 
no se predeterminó; fue una derivación de los contactos iniciales. De esta manera entrevistamos a médicos, sicólogos, abogados, administradores, contadores y profesionales de otras disciplinas. Ciertas pautas para seleccionar a los entrevistados, como buscar variedad en el lugar de residencia (centro o periferia), el tipo de hogar (familiar o no), el grupo de edad y el género, favorecieron la participación de profesionales con perfiles sociodemográficos diferentes.

En las entrevistas se abordaron varios temas; entre ellos destacaron el nivel de satisfacción respecto a la vivienda actual y su entorno, y la percepción de los profesionales sobre el centro antiguo como medio residencial y sobre sus habitantes. Se perseguían tres objetivos específicos:

1) Evaluar las percepciones de los profesionales acerca de "vivir en el centro antiguo de Puebla".

2) Comprobar si los profesionales que viven en el centro antiguo de Puebla responden a las características de los "residentes de siempre" o a las de una población que se reapropia de las áreas centrales.

3) Evaluar qué tanto interés podrían tener los profesionales que viven fuera del centro sobre un posible "regreso".

La duración de cada entrevista fue aproximadamente de 60 minutos y se grabó en un medio magnetofónico. Asimismo los entrevistados llenaron un calendario de movilidad residencial y profesional para complementar la base de datos. Los resultados que se presentan aquí provienen de las grabaciones de la primera parte (nivel de satisfacción respecto a la vivienda y su entorno), y del contenido de las entrevistas relacionado específicamente con "los barrios centrales como entorno residencial y sus residentes".

Presentamos varios extractos que ilustran casos tipo de un punto de vista que compartieron varios profesionales; sin embargo en algunos casos se muestra el particular punto de vista de un entrevistado. De la misma forma, los cuadros que cuantifican las menciones sirvieron para evaluar los aspectos que resaltaron con mayor frecuencia en las declaraciones de los entrevistados con el interés de evaluar la importancia de ciertas características en su discurso, pues esto incide sobre su representación del centro histórico. Conviene recordar que el objeto central del análisis de esta encuesta, la percepción, se sitúa en la génesis del proceso de representación. Nuestro interés ha sido determinar 
si los profesionales entrevistados han percibido las transformaciones del centro antiguo, algo que a nuestro parecer es esencial en la construcción de una imagen positiva de los lugares. Finalmente, para este análisis se tomaron en cuenta las opiniones de personas clave en la comprensión del tema.

\section{Resultados}

\section{¿Cuál centro?}

Para los fines de la encuesta la zona central fue definida como el área accesible a pie (en un radio de $2 \mathrm{~km}$ ) desde la plaza central en donde se sitúa el Zócalo (mapa 2). Aunque se pretendía que la terminología utilizada en las entrevistas fuese neutra, tuvo sin embargo repercusiones sobre ellas. Así, al pedir a los profesionales que expusieran sus impresiones sobre los barrios centrales (término genérico) y el centro (la zona central), ellos hablaron largamente sobre las distinciones entre el Centro (límites administrativos del barrio), los barrios y las colonias que están incluidos totalmente o en parte en la zona patrimonial. Fue también frecuente que hablaran indistintamente del Centro con límites relativamente extendidos, y del centro histórico, que corresponde a los límites de la zona patrimonial. Entienden que la noción de centro histórico corresponde a la ciudad española. A pesar de que los antiguos barrios indígenas y las colonias colindantes con la zona patrimonial suelen considerarse barrios históricos, se excluyen casi sistemáticamente de la noción de centro histórico debido a la influencia de una representación de los barrios (antiguos barrios indígenas) que parece haberse heredado del pasado. Históricamente la diferenciación étnica (y económica) entre los barrios y la ciudad española estaba anclada en el territorio. La diferenciación territorial de los colonos españoles y sus descendientes respecto a la población indígena y su modo de vida se percibe en el ordenamiento urbano, en la arquitectura, y en la prestación de los servicios públicos. Por ejemplo, varios de estos barrios fueron conectados apenas en el siglo XX a la infraestructura de alcantarillado y agua potable (García Palacios de Juárez, 1995).

Estas observaciones no son impresionantes, pero sí lo es que la generalidad de la situación no se hubiera previsto en las respuestas del cuestionario sobre las aspiraciones residenciales. A primera vista todo lleva a pensar que nos encontramos con una fuerte representación 
social de la zona central, lo cual puede afectar la percepción de los esfuerzos de revitalización. Los análisis de los resultados de esta encuesta cuantitativa necesariamente han tomado en cuenta la distinción hecha por los entrevistados.

\section{Vivir en el centro}

Según dice un importante empresario inmobiliario (Bojalil Andrade, 2001), ${ }^{7}$ tradicionalmente los miembros de la clase media alta poblana han preferido establecer sus residencias en la periferia del Centro, dentro de los fraccionamientos cerrados. Las clases media y media inferior parecen tolerar más fácilmente los inconvenientes del Centro, pues aprecian sus ventajas como lugar de trabajo y de consumo. Bojalil Andrade agrega que parece existir una demanda adicional proveniente del exterior de la ciudad, sobre todo de la Ciudad de México y algunas del extranjero, para instalar viviendas de lujo en los barrios centrales. Sin embargo esto se ve desalentado por los costos de restauración y modernización, que aunados a la complejidad de los trámites administrativos, a la escasa oferta de vivienda en el Centro, y al desinterés de los propietarios actuales de los edificios (patrimoniales o no) por el mercado de vivienda en el lugar (Durán Guzmán, 2001) ${ }^{8}$ menguan esta demanda. Una interpretación abusiva de la ley de vivienda ha dificultado y en ciertos casos impedido la expulsión de los inquilinos morosos, y ha incitado a los propietarios a dar a sus propiedades otros usos que les son mucho más rentables, y así prefieren convertir los inmuebles residenciales en comercios o espacios de oficinas.

Seis de los profesionales entrevistados viven en el Centro. Tres desde siempre y los otros tres desde hace algunos años. Otro de ellos vive a sólo diez cuadras de la plaza central (Zócalo), pero fuera del Centro. Estos siete residentes del área central comparten una apreciación positiva de su medio residencial en la que destacan sobre todo la disponibilidad de los servicios públicos (particularmente el aseo de las calles y el alumbrado) y de los servicios de transporte, la proximidad de todo, la arquitectura y el patrimonio. Las opiniones sobre la inseguridad, las actividades comerciales, el mantenimiento de los edificios, biliaria.

${ }^{7}$ Entrevista con el señor Ernesto Bojalil Andrade, director general de Altiko Inmo-

${ }^{8}$ Entrevista con el arquitecto Pablo Durán Guzmán, subdirector de investigación del Consejo del Centro Histórico de la Ciudad de Puebla. 
MAPA 2

\section{La zona central de Puebla}

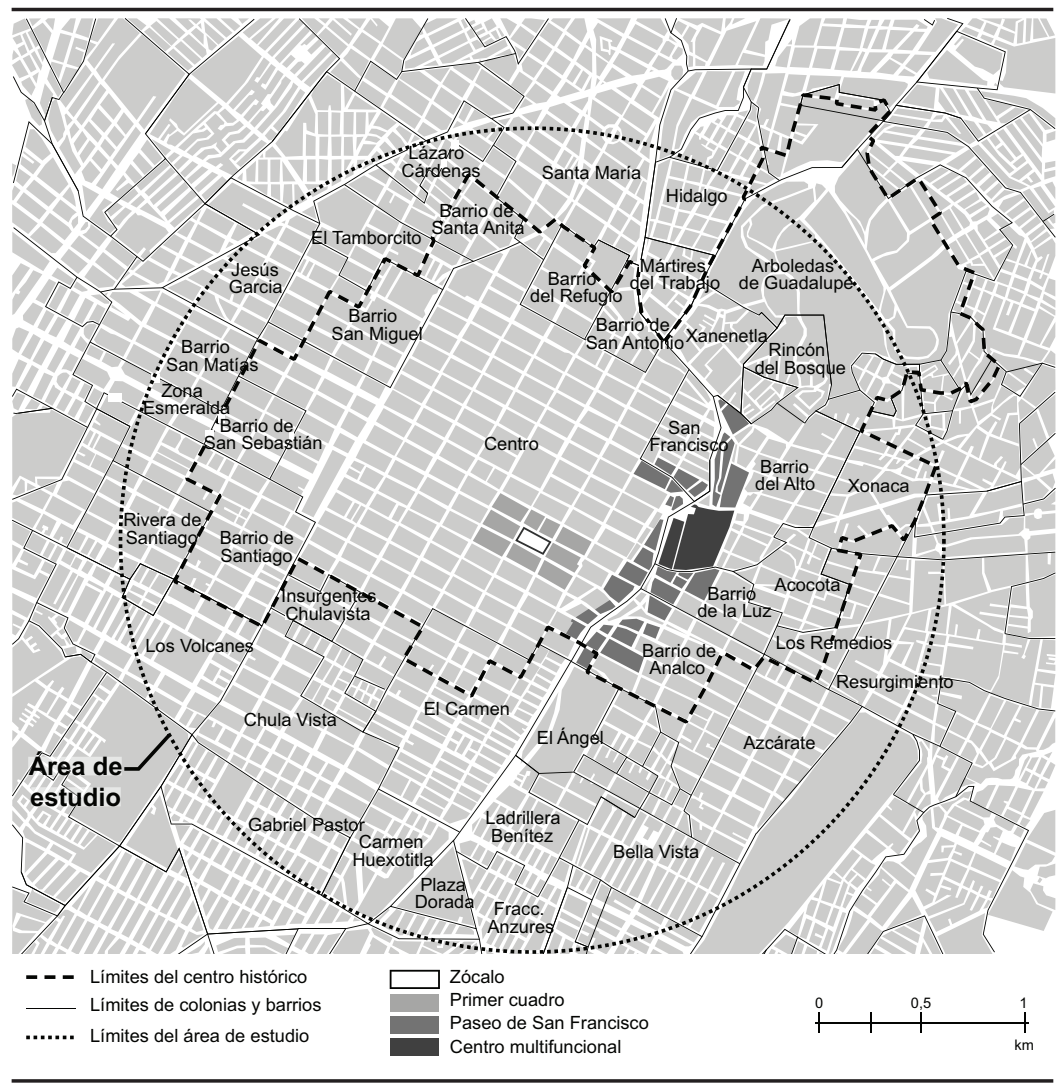

el ruido y el servicio de agua potable están más divididas (cuadro 1). Pese a los aspectos negativos, los residentes recientes parecen haber elegido vivir en el centro más que por la representación simbólica, por su localización óptima, cuyas ventajas rebasan los inconvenientes. También aprecian sus cualidades arquitectónicas y patrimoniales.

$\mathrm{Al}$ analizar los aspectos mencionados por los residentes del centro se observa que siete de diez son positivos. Elsa, una sicóloga de 32 años que vive sola, llegó recientemente al Centro. La evaluación que hace de su medio residencial resume bien los aspectos positivos que mencionan los siete entrevistados, sin que por ello olviden sus defectos. 


\section{CUADRO 1}

\section{Percepciones de las ventajas e inconvenientes de vivir en el centro antiguo}

Ventajas

\begin{tabular}{lclc}
\hline Menciones de los 7 residentes & Núm. & Menciones de los 26 no residentes & Núm. \\
\hline - Transporte & 9 & • Todos los servicios & 12 \\
- Todos los servicios & 8 & • Proximidad de todo & 11 \\
- Seguridad & 4 & • Arquitectura, imagen urbana & 9 \\
- Alumbrado público & 4 & • Comercios & 6 \\
- Arquitectura, imagen urbana & 4 & - Infraestructura cultural & 5 \\
(29 de 51 ventajas mencionadas) & & $(43$ de 60 ventajas mencionadas) &
\end{tabular}

Inconvenientes

\begin{tabular}{lclc}
\hline Menciones de los 7 residentes & Núm. & Menciones de los 26 no residentes & Núm. \\
\hline - Seguridad & $4^{*}$ & $\bullet$ Seguridad & 11 \\
- Comercios & 4 & $\bullet$ Mantenimiento de los edificios & 10 \\
- Agua & 2 & - Tráfico y congestión & 9 \\
- Mantenimiento de los edificios & 2 & $\bullet$ Ruido & 8 \\
- Reglas y normas del Instituto & & $\bullet$ Vivienda & 8 \\
$\quad$ Nacional de Antropología & 2 & & \\
e Historia & & \\
(14 de 21 inconvenientes mencionados) & (46 de 91 inconvenientes mencionados) \\
\hline
\end{tabular}

* Dos son "no exclusivas para el Centro" y las otras dos las hizo la misma persona, quien vivió un incidente en el Centro.

FUENTE: Elaboración propia con base en entrevistas a profesionales poblanos.

Mi colonia es muy tradicional porque es el Centro. Te imaginarás, entonces, que el Centro tiene de todo; pero desafortunadamente también carece de todo. A veces, carece de alumbrado público, de necesidades primordiales como el agua, como [...] la seguridad principalmente [...] En este momento hay desconfianza, en muchas ocasiones el Centro es inseguro. [Lo que me agrada es que] todo lo tienes a la mano. Ése es el gran beneficio. A la vuelta de cualquier cuadra encuentras lo que necesitas, no tienes ningún problema para encontrar lo que requieres. [Lo que me desagrada es] que los domingos todo en el Centro está cerrado y no encuentras nada.

Yo siento que sí hay seguridad, pero encuentras ciertos elementos [inseguros]. En determinadas zonas del Centro no puedes dejar tus unidades [microbuses] porque inmediatamente das la vuelta y te asaltaron [...] He pasado por cinco asaltos exactamente en el Centro [...] y nunca he encontrado un policía $[\ldots]$ 
No sufrimos en el Centro, afortunadamente, de falta de mantenimiento en los servicios [...] Yo creo que el agua es el único servicio que presenta problemas, porque por lo regular no tenemos agua [...] Después que salgo para ir a trabajar, cae una hora y es muy poca el agua [...] Cuando llego en la noche, yo no tengo agua para poderme lavar los dientes y mucho menos las manos. Éste es el único problema que yo siento que hay aquí.

Entre los no residentes sólo 5 de un total de 26 habían vivido antes en el área central; de éstos, 3 siguen conservando una opinión positiva del centro de la ciudad. Las excepciones son Jaime y Martín. Las razones por las cuales dejaron el centro no son claras. Jaime se dedica a la informática, tiene 47 años, es casado, padre de dos hijos y partió de la colonia El Carmen (antiguamente Barrio del Carmen) con su familia con el fin de habitar en una propiedad dentro de un fraccionamiento cerrado, lejos del Centro. Martín es un contador de 48 años, casado y padre de dos hijos, que dejó el Centro porque su vivienda ya no satisfacía las necesidades de su familia y tuvo la oportunidad de adquirir un departamento más acorde con lo que requería en ese momento; finalmente primó su decisión de relocalización residencial.

Los trabajos sobre movilidad residencial identifican varios incentivos que influyen en las decisiones de localización residencial, entre los cuales destaca cierta insatisfacción respecto a la vivienda o a su entorno físico y social (Rossi, 1980; Brown y Moore, 1970). Aun cuando Jaime y su familia residían en un departamento agradable con todos los servicios, tenían buenos vecinos y habían logrado el reconocimiento de los comerciantes locales, estaban insatisfechos porque les molestaban otras características de su entorno como el ruido incesante del tráfico, los vendedores ambulantes y la contaminación atmosférica. Deseaban alejarse de eso aunque el precio a pagar fuera prescindir de las ventajas que les daba el Centro.

Los no residentes perciben ciertas características positivas de la vida en el Centro: la proximidad de todo, la belleza de su arquitectura, la infraestructura cultural y de entretenimiento, los comercios y los servicios. No obstante, algunas percepciones negativas, reales o no, nos recuerdan las particularidades que hacen a los centros antiguos latinoamericanos menos susceptibles a la regeneración sociorresidencial (Jones y Varley, 1999; Ward, 1993), como la falta de limpieza, el escaso mantenimiento de los edificios, el tráfico, la congestión, el ruido y la mala calidad de la vivienda. Estas características harían del centro un lugar inadecuado para vivir (cuadro 1). La falta de seguridad era el 
problema más grave para seis de los entrevistados, pero en realidad sólo uno ha sufrido ese problema; dos fueron testigos o vivieron incidentes de ese tipo en el Centro y otros dos no consideran muy seguro su propio vecindario. Entre ellos Silvia, enfermera especializada de 38 años y madre monoparental que ha vivido siempre en la casa de sus padres, resume en su entrevista buena parte de las percepciones negativas que mencionan los no residentes.

No me gustaría porque, como es el Centro, toda la gente va allá. Hay mucha gente, hay mucho tráfico. Me gustaría vivir en un lugar tranquilo. Yo creo que tiene lo necesario: agua, luz, lo necesario. La verdad no sé si hay luz, si hay agua, cuáles días, o qué. De lo que sí me he dado cuenta es que hay mucha basura en las calles. A veces hay muchos hoyos, hay algunas casas deterioradas, así se ve feo. [La seguridad] está mal porque, le digo lo que veo, a veces te roban la bolsa [...] A veces, no hay personas para auxiliarlo a uno [...] Por ejemplo, una vez [vi] a una señorita con su bolsa y una persona en su bicicleta que le arrebató la bolsa [...] Si [tengo] la oportunidad [de vivir en el Centro] iré solamente por alguna necesidad. Así de irme, no.

Igual que en la encuesta por cuestionario, las entrevistas revelaban que los hogares de clase profesional se mostraban interesados en vivir en el centro histórico. Cerca de la cuarta parte de los profesionales, tanto los entrevistados como los encuestados, manifestaron que les gustaría vivir en ese lugar. Ocho profesionales que no viven actualmente en el Centro declararon que les gustaría vivir allí. Éste es, por ejemplo, el caso de Martín, quien vivió en el Centro a fines de los años ochenta.

Yo creo que vivir por allá está muy bien. Se tiene todo a la mano en el Centro, puedes ir caminando y buscar una farmacia, buscar un servicio de urgencia y todo. Es la ciudad y hay movimiento y todo. Es muy recomendable estar por allá y no en las periferias que no tienen nada y donde debes buscar un taxi para cualquier cosa. Hay más seguridad porque es el Centro. Hay más de todo [...] Yo creo que hay inseguridad en todas partes. Yo creo que en todas partes existen zonas [...] ya viste en El Mirador, ya viste en La Paz y todos los lugares donde está la tentación [...] porque son viviendas con gente que tiene dinero.

En resumen, según opinan los residentes del Centro, éste es un lugar adecuado para vivir y sus ventajas son las siguientes: la proximidad de todo, incluyendo gran número de comercios y todos los servicios públicos; 
el alumbrado y la limpieza de las calles; la facilidad en el transporte; la buena vigilancia policiaca (a pesar de que la inseguridad sigue constituyendo un problema para los habitantes del Centro y para los moradores de otros sectores de la ciudad); y finalmente la belleza de la arquitectura, el patrimonio e incluso ciertas características propias de las viviendas antiguas, como la altura de los techos, la amplitud de las habitaciones, y los materiales con que se construyeron las viviendas. Éstas, entre otras, constituyen ventajas apreciables para su revitalización.

Dice Milián Ávila (1994) que el centro histórico posee un gran valor simbólico para los poblanos. Fue el lugar donde se fundó la ciudad en 1531 y en la actualidad sigue siendo un centro político, religioso y cultural (Melé, 2003) que concentra numerosas actividades económicas, de ahí que sea muy concurrido por todas las clases sociales de la ciudad. Sin embargo, 19 entrevistados no residentes en el lugar consideran que los atractivos de vivir en el centro (proximidad de todo, bella arquitectura, infraestructura cultural, etc.) no compensan sus inconvenientes, entre ellos el ruido, el tráfico, la densidad de las construcciones, la contaminación, la falta de limpieza y algunas características de las viviendas como la falta de agua y la antigüedad de las construcciones. Sin embargo los resultados de las entrevistas analizadas muestran una polarización de los residentes y los no residentes en cuanto a la valoración del centro histórico. Mientras que las razones principales que explican el deseo de vivir en el centro histórico están relacionadas con los comercios, los servicios, las actividades económicas, la arquitectura, el patrimonio y el transporte; las razones que explican que la gente no desee vivir allí se relacionan con los problemas de tráfico y de estacionamiento, de infraestructura y de servicios públicos, las viviendas inadecuadas y, por último, el alto nivel de ruido.

\section{¿Quién habita el Centro?}

Diferencias de percepción según el lugar de residencia

La apreciación del centro antiguo que tienen los profesionales difiere según sean o no residentes. Sin embargo la percepción de varios no residentes coincide con la evaluación de los residentes respecto a la heterogeneidad social del Centro (cuadro 2). Dicha heterogeneidad, sostienen Jones y Varley (1999), puede ser vista como un obstáculo a la regeneración sociorresidencial de la zona central antigua. 


\section{CUADRO 2}

Percepción de la composición social del centro antiguo según el lugar de residencia del encuestado

\begin{tabular}{lcc}
\hline & Residentes (7) & No residentes (26) \\
\hline De todo & 5 & 7 \\
Ricos & 2 & 2 \\
Clase media & 1 & 1 \\
Escasa educación, escasa cultura & 1 & 1 \\
Pobres & 1 & 5 \\
Por costumbre, falta de oportunidad & 0 & 9 \\
Trabajadores y comerciantes & 1 & 8 \\
Turistas, gente de paso & 0 & 4 \\
Viejos & 0 & 1 \\
Gente tranquila y agradable & 1 & 2 \\
Profesionales & 0 & 1 \\
Total de las menciones & 12 & 41 \\
\hline
\end{tabular}

FUENTE: Elaboración propia con base en entrevistas a profesionales poblanos.

Dicen quienes residen en el centro de Puebla que allí habita toda clase de personas, desde los propietarios de hermosas casas coloniales, las clases medias, trabajadores, pobres y gente de escasa educación. Parece que no todas las "grandes familias" de ascendencia española abandonaron el Centro a partir de 1940 para habitar en los nuevos barrios elegantes en la periferia (véase Méndez, 1987). Elsa resume las apreciaciones de los residentes del Centro sobre su entorno social.

Tiene de todo [...] Últimamente, me estoy dando cuenta que ya muy poca gente renta sus casas. Entonces, ya los mismos dueños ocupan toda la casa. Hay muchos propietarios de casas muy grandes y de verdaderas casas coloniales. Cuando buscas departamento lo haces teniendo en cuenta la colonia. pero en realidad te das cuenta en su momento que no es cierto, que es mentira. Las apariencias te engañan. Entonces, como en todos lados no es la ubicación adecuada, pero sea como sea, en cualquier lado te encuentras de todo. Tanto buenos como malos, como... de todo. En todos los aspectos te encuentras de todo. En el Centro hay de todo, como en todas las colonias, como en todos lugares.

Algunos de los entrevistados observan que los que viven allí, o buena parte de éstos, siguen en el Centro por costumbre o por falta de oportu- 
nidad. Elena resume bien esta imagen que tienen los profesionales no residentes acerca de la población que habita en el centro de Puebla.

Yo creo que la poca gente que queda, que vive actualmente en el Centro, son personas que no tienen otro lugar adonde ir y que viven en las casas viejas y no restauradas. Ellos tienen la necesidad de vivir allí porque las casas tienen muy malas condiciones y los servicios son malos, sobre todo el agua. Pero en las casas donde han hecho restauraciones y tienen remodelación reciente vive más bien gente de ingresos altos, de clase alta.

Según Francisco, joven abogado que vivía en la colonia El Carmen antes de casarse en 1993, es más una cuestión de costumbre: "La gente que vive en esos lugares ha sido gente que tiene sus raíces en esos lugares. Son gente que ha vivido allí toda la vida y que no se ha traslado de un lado al otro".

En resumen, el Centro alberga a una población mixta que incluye a todas las clases sociales. Muchos propietarios ricos gozan de ese ambiente arquitectónico y urbanístico reconocido por la UNESCO, así como trabajadores de todos los niveles sociales, entre quienes no faltan los que viven en condiciones precarias. Todos aprovechan las facilidades de transporte que ofrece el Centro.

\section{¿Y los demás barrios centrales?}

Desde su fundación los barrios (antiguos barrios indígenas) fueron percibidos como lugares distintos de los que integraban la ciudad española. El crecimiento urbano acabó por absorberlos y se perdió su ordenamiento en forma de laberinto al cambiarse por una trama octogonal. Pese a ello algunos parecen no haber sufrido cambios importantes (éste era el caso del Barrio del Alto, antes del proyecto Paseo de San Francisco). En otros barrios vive una población mixta (Barrio Analco) y en algunos otros, como el Barrio Santiago, se construyeron condominios horizontales rodeados por un muro (conjuntos cerrados) destinados a las clases medias y superiores (Milián Ávila, 1994). ${ }^{9}$

De los profesionales entrevistados, Erik es el único que vive en un barrio. Este ingeniero en electrónica divorciado habita desde 1985 un

${ }^{9}$ Entrevista con la profesora investigadora Guadalupe Milián Ávila, de la Universidad Autónoma de Puebla, quien acaba de terminar un estudio del Barrio Analco y ha trabajado sobre los barrios cerrados de Puebla. 
departamento que pertenece a sus abuelos y se localiza en Xonaca, uno de los barrios incluidos en parte de la zona patrimonial. Opina que su medio residencial ha mejorado desde que vive allí, aunque expone ciertas críticas en cuanto a su entorno físico y social.

Defectos... tienes bastante allí, como en todo Puebla. Los baches en las calles que están pavimentadas; las calles que no tienen alumbrado público. En cuanto a la seguridad, sí hay un poco, pero sería necesaria más. Me pintaron mis paredes, hacen grafitis, me robaron cristales, se metieron a robar a mi casa. Yo calculo que es gente de la colonia, además aquí hay un problema social muy fuerte con el alcoholismo. Precisamente a la vuelta de mi casa mucha gente es alcohólica y se la pasan tomando todo el tiempo. Eso ayuda a cometer delitos, a robar. No hay la seguridad necesaria. Las patrullas vienen, pero no existe seguridad. No te puedes ir de vacaciones quince días fuera de tu casa $[\ldots]$ Por el alumbrado, está bien. ¿Por el acceso? Estamos a dos calles del boulevard Xonaca... pasan bastantes rutas. Muy pocas calles no están pavimentadas. El problema de seguridad no tiene que ver con el alumbrado, sino con las pandillas; éstas son peligrosas $[\ldots]$

El barrio me gusta. La zona me gusta. Llevo acá ya más de 17 años. Me gusta la zona. También es muy cómodo porque la casa pertenece a la familia.

La apreciación que hace Erik de su entorno físico y social no está muy alejada de la que expusieron los demás profesionales entrevistados. Lo que más resalta en las entrevistas es la representación que evoca la noción de barrio. Según los entrevistados son lugares antiguos, tradicionales, en los que la población sigue un modo de vida distinto; son lugares peligrosos en donde se concentran ciertos problemas sociales como el alcoholismo, el consumo de drogas y el pandillerismo, sin embargo son víctimas de su mala reputación. María, que ha vivido desde siempre en el Centro, observa: "Yo creo que a lo mejor la gente es buena pero tiene su fama. Y eso depende de los padres, de la educación que tienen [...] Los barrios son bonitos. Tienen su historia, su manera de vivir también. Como son más de épocas anteriores [...] son muy tradicionales".

Julia, abogada de 23 años que vive en la periferia de la ciudad, reconoce que quizás equivocadamente percibe a los barrios como lugares peligrosos. Muchos de los profesionales entrevistados comparten esa imagen de peligro y de modo de vida diferente. Miguel es uno de ellos; según él: 
Hay mucho vandalismo. Hay lugares, hay espacios de esos lugares que la verdad da tristeza verlos. Ésta es nuestra realidad y hay mucha gente de escasos recursos económicos que incluso vive también allí. Culturalmente, pues a lo mejor, tiene su propia cultura pero casi de barrio a barrio no se quieren y empiezan a pelearse. Yo creo que por esa misma razón existen muchos asesinatos, muchos lugares donde es mejor no pasar [...] Si viene alguien que no es del barrio, definitivamente [tiene problemas].

Esta referencia al peligro aparece incluso en algunos textos que relatan la historia de los barrios en el siglo XVII. Así: "una característica de los habitantes de los barrios [énfasis nuestro] era su peligrosidad, la que, en general, se traducía en fanatismo; sin embargo, tenían exacta conciencia de sus deberes cívicos, respeto a sus autoridades civiles y anhelo de mejoramiento" (García Palacio de Juárez 1995: 143). No obstante estos textos refieren muy pocos incidentes que demuestren la "peligrosidad" de la población de los barrios.

Aun cuando los barrios siguen llevando a cuestas esa imagen negativa, no todos nuestros entrevistados opinan lo mismo. Para varios de ellos son lugares hermosos pero carentes de mantenimiento e infraestructura. Según Francisco, la situación parece incluso haber mejorado:

Los conozco. He tenido la oportunidad de estar por allí en algunas ocasiones. De hecho mi esposa vivió varios años allí en el Barrio de los Remedios, cercano al Alto, a La Luz, a la Acocota [y] todo eso. Yo creo que son lugares que se han ido mejorando en cuanto a su modo de vida y en cuanto a lo que es el mantenimiento y distribución de servicios.

La percepción de que el modo de vida y la cultura son diferentes en los barrios limítrofes de la zona patrimonial parece obstaculizar su apropiación por la clase profesional. Como aseguran Kearns y Parkinson (2001), un barrio (utilizamos aquí el término genérico) puede estigmatizar a su población residente haciendo que su mala reputación frene su revitalización. El megaproyecto de revitalización Paseo de San Francisco, que fue mencionado únicamente por una profesional, no parece haber logrado cambiar el sentimiento de peligro que inspiran los barrios. No se desecha que los cambios sean posibles en el largo plazo, pero tardarán en manifestarse. 


\section{Conclusión}

Los entrevistados que residen en el centro antiguo están satisfechos con su modo de vida. Pese a que reconocen que existen problemas por el ruido, la contaminación, el deficiente servicio de agua y cuestionable nivel de seguridad, consideran que las ventajas de la localización central y la proximidad de todos los comercios, servicios e infraestructura superan a los inconvenientes. Los no residentes advierten las ventajas de una localización residencial central, pero su imagen de las características del área parece alejarse de la realidad que viven los residentes. Es así en lo que se refiere a la seguridad, el servicio de limpieza cotidiano y los servicios de agua y recolección de desechos. Para la mayoría de nuestros entrevistados el centro histórico y los barrios son lugares peligrosos.

La encuesta no reveló un perfil tipo en los residentes del Centro. Éstos responden a dos perfiles de movilidad: residentes de siempre y recién llegados. Tampoco reveló una diferenciación entre los residentes y los no residentes en cuanto a los perfiles familiares, la historia de movilidad residencial o los lugares de trabajo. Los residentes de siempre son individuos y familias que no migraron rumbo a nuevos barrios. Los no residentes piensan que estos profesionales no sienten la necesidad de partir porque tienen sus raíces en el Centro, porque no conocen otros lugares o porque carecen de oportunidades. Los demás profesionales residentes son recién llegados. Pese a su pequeño número podría comparárseles con los "pioneros urbanos" en el sentido de Smith (1996), o con los "gentrificadores marginales" en el sentido de Rose (1996). Sin embargo aún sería prematuro afirmar que anuncian un movimiento más importante de renacimiento sociorresidencial, por lo que podría tratarse únicamente de casos aislados.

Un número no desdeñable de profesionales no residentes considera que el centro histórico de Puebla reúne ventajas suficientes para estimular el deseo de vivir allí, entre ellas la proximidad de todo, su bella arquitectura, las infraestructuras cultural y de entretenimiento, muchos comercios y servicios. Este interés resulta más significativo cuando lo evocan los antiguos residentes que partieron. Pese a esta atracción por el centro histórico, la oferta de vivienda no ha podido responder a sus necesidades, a sus esperanzas y a sus aspiraciones residenciales. Varios entrevistados manifiestan que pese a la demanda para la vivienda de lujo en el centro histórico, la oferta es escasa. La falta de liderazgo de las autoridades en la gestión de la ocupación del 
suelo y la vivienda, así como una estrecha visión de los propietarios de los edificios, sumadas a las grandes erogaciones que implican la rehabilitación y la modernización de los inmuebles en alquiler, han fomentado la proliferación de otras actividades en las casas coloniales. Como observaron Jones y Varley (1999), todo esto ha favorecido una forma distinta de regeneración centrada en los comercios y en las infraestructuras culturales.

Esta encuesta cualitativa, basada en entrevistas a profesionales poblanos, ha revelado que muchos de ellos tienen una percepción negativa, en ocasiones imaginada, del centro histórico como medio de vida, lo cual podría obstaculizar el renacimiento sociorresidencial de éste. Para ellos la ciudad española del centro histórico no forma parte de los "buenos vecindarios" o barrios adecuados, aun cuando los residentes actuales estén satisfechos, e incluso varios de los no residentes hayan manifestado su interés por vivir allí.

En cuanto a los demás barrios del centro, la poderosa representación negativa que sobre ellos recae es una herencia del pasado. Tan mala es su reputación que amenaza con frenar cualquier proyecto de revitalización que se pretendiera desarrollar. Para terminar, esta encuesta ha puesto en evidencia que nuestros profesionales no hicieron referencia alguna a los diversos programas de revitalización del Centro, los cuales habrían podido colaborar para la construcción de una imagen positiva de este lugar como ambiente residencial.

\section{Bibliografía}

Bélanger, H. (2005), “Will Professionals 'Return' to the Centre of Latin American Cities? The Residential Aspirations of Professional Households in Puebla, Mexico", Anuario de Espacios Urbanos. Historia, Cultura, Diseño, núm. 13, pp. 232-259.

Bélanger, H. (2006), "La dynamique sociorésidentielle d'une ville latino-américaine. L'application d'une analyse en grappes à la ville de Puebla au Mexique", Cahiers de Géographie du Québec, vol. 50, núm. 139, pp. 45-63.

Bidou-Zachariasen, C. (dir.) (2003), Retours en ville, París, Descartes \& Cie.

Bojalil Andrade, E. (2001), "Entrevista con el Sr. Ernesto Bojalil Andrade, director general, Altiko inmobiliaria", Puebla, ms.

Bourdin, A. (1984); Le patrimoine réinventé, París, Presses Universitaires de France (Espace et liberté).

Brown, L.A. y E.G. Moore (1970), "The Intra-Urban Migration Process: a Perspective”, Geografiska Annaler, vol. 52, núm. B, pp. 1-13. 
Caufield, J. y L. Peake (1996), City Lives and City Forms: Critical Research and Canadian Urbanism, Toronto, University of Toronto Press.

Choay, F. (1992), L'allégorie du patrimoine, París, Éditions du Seuil.

Durán Guzmán, P. (2001), "Entrevista con el arquitecto Pablo Durán Guzmán, subdirector de investigación, Consejo del Centro Histórico de la Ciudad de Puebla”, Puebla, ms.

Galster, G. (2001), "On the Nature of Neighborhood, Urban Studies, vol. 38, núm. 12, pp. 2111-2124.

García Palacios de Juárez, E. (1995), Los barrios antiguos de Puebla, Puebla, Gobierno del Estado de Puebla, Secretaría de Cultura.

Gilbert, A. y A. Varley (1990), "The Mexican Landlord: Rental Housing in Guadalajara and Puebla, Urban Studies, vol. 27, núm. 1, pp. 23-44.

Guerrero Lozano, J. (2000), Patrimonialisation et "marchandisation” des quartiers anciens: le cas de Los Sapos à Puebla (Mexique), tesis de doctorado en Estudios Urbanos, Montreal, Université du Québec, INRs-Urbanisation.

Hiernaux, D. (2007), "Los imaginarios urbanos: de la teoría y los aterrizajes en los estudios urbanos", Eure, núm. 33, pp. 17-30, pp. 17-30.

Jones, G.A. y A. Varley (1999), "The Reconquest of the Historic Centre: Urban Conservation and Gentrification in Puebla, Mexico", Environment and Planning A, vol. 31, pp. 1547-1566.

Kearns, A. y M. Parkinson (2001), "The Significance of Neighbourhood”, Urban Studies, vol. 38, núm. 12, pp. 2103-2110.

Ley, D. (1996), “The New Middle Class in Canadian Central Cities”, en J. Caufield y L. Peake (eds.), City Lives and City Forms: Critical Research and Canadian Urbanism, Toronto-Buffalo-Londres, University of Toronto Press, pp. 15-32.

Lindón, A., M.A. Aguilar y D. Hiernaux (coords.) (2006), Lugares e imaginarios en las metrópolis, Barcelona, Anthropos/Universidad Autónoma Metropolitana, Iztapalapa.

Melé, P. (2003), “(Ré)investir les espaces centraux des villes mexicaines”, en C. Bidou-Zachariesen (dir.), Retours en villes, París, Descartes \& Cie.

Méndez, E. (1987), La conformación de la ciudad de Puebla (1966-1980). Una visión histórica, Puebla, Universidad Autónoma de Puebla (Historia).

Milían Ávila, G.M. (1994), La modernización sistémica. La desconcentración comercial en la ciudad de Puebla, Puebla, Benemérita Universidad Autónoma de Puebla.

Milían Ávila, G.M. (1994), "Entrevista con la profesora-investigadora Guadalupe Milián Ávila de la Universidad Autónoma de Puebla”, Puebla, ms.

Monnet, J. (1994), "Centres historiques et centres des affaires: la centralité urbaine”, Problèmes d'Amérique Latine, núm. 14, pp. 83-101.

Paz Arellano, P. (1999), El otro significado de un monumento históricos, México, Conaculta/INAH (Divulgación).

Prochansky, H.M. (1978), "The City and Self-Identity", Environment and Behavior, núm. 10. 
Rose, D. (1996), "Economic Restructuring and the Diversification of Gentrification in the 1980s: a View from a Marginal Metropolis", en J. Caufield y L. Peake (eds.), City Lives and City Forms: Critical Research and Canadian Urbanism, Toronto-Buffalo-Londres, University of Toronto Press, pp. 131-172.

Rossi, P.H. (1980), Why Families Move, 2a ed., Berverly Hills-Londres, Sage Publications.

Schteingart, M. (1989), Los productores del espacio habitable. Estado, empresa y sociedad en la Ciudad de México, México, El Colegio de México, Centro de Estudios Demográficos y de Desarrollo Urbano.

Silva, A. (1992), Imaginarios urbanos, Bogotá y São Paulo: cultura y comunicación urbana en América Latina, Bogotá, Tercer Mundo.

Silva, A. (2006), "Centros imaginados de América Latina", en A. Lindón, M.A. Aguilar y D. Hiernaux (coords.) (2006), Lugares e imaginarios en las metrópolis, Barcelona, Anthropos/Universidad Autónoma Metropolitana, Iztapalapa, pp. 43-65.

Smith, N. (1996), The New Urban Frontier. Gentrification and the Revanchist City, Londres-Nueva York, Routledge.

Suttles, G. (1972), The Social Construction of Community, Chicago, University of Chicago Press.

Téllez Morales, B.R. (1998), "El Centro Histórico y sus transformaciones en la metropolización contemporánea. El paso del río de San Francisco del Programa Angelópolis, Puebla", en XXIVe Colloquio de l'Association de Science Régionale de Langue Française: Régions, Villes et Développement, Puebla, 3 a 6 de septiembre.

Ward, P.M. (1993), "The Latin American Inner City: Differences of Degree or of Kind?", Environment and Planning A, vol. 25, núm. 8, pp. 1131-1160.

Xiberras, M. (2002), Pratique de l'imaginaire. Lecture de Gilbert Durand, Sainte-Foy, Les Presses de l'Université Laval (Lectures). 